\title{
Fixed-to-Mobile Substitution, Complementarity and Convergence
}

\section{Rob Albon}

$\mathrm{T}$ The relationship between fixed-line and mobile networks is often depicted as one of fixed-to-mobile (FTM) substitution, where fixed-line services and calls are replaced by mobile subscription and calling. While this is intuitively appealing, the relationship between the fixed-line and mobile networks can only be understood by careful examination of what is happening within each network (including intra-network substitution and complementarity) and what is happening between them (to encompass complementarity and convergence as well as substitutability). A proper understanding of the relationship has important implications for regulatory policy and effective competition in the supply of telecommunications services.

The linkages and processes within each network and between networks are discussed in the context of countries that:

- had highly-developed fixed-line networks (over 90 per cent household penetration) before the advent of mobile telecommunications;

- $\quad$ use the calling party pays (CPP) pricing system rather than the receiving party pays (RPP) used in North America; and

- have reached a high level of mobile penetration (around 90 per cent of the population) after about fifteen years of development of mobile telecommunications.

Australia, New Zealand and the United Kingdom are good examples of countries exhibiting these three characteristics.

It is argued in this paper that a fixation on fixed-to-mobile substitution and less than a thorough understanding of complementarity can lead to misleading conclusions and inefficient decision making. For example, gloomy accounts of the fixed-line business (overlooking the migration from narrowband to broadband) are often used to support a deregulatory stance. In relation to mobiles, often elaborate arguments for very high charges for completing calls on mobile networks are weakened by the recognition of complementarity. This analysis can also help allay fears of the so-called 'waterbed effect' (discussed later).

Rob Albon is Senior Economic Adviser, Regulatory Development, with the Australian Competition and Consumer Commission. 


\section{Background}

A call from a fixed line service to a mobile telephone service is made up of initiation and carriage of the call over the fixed network, transfer of the call from the fixed to the mobile network, and carriage of the call to the receiving party over the mobile network. The last component is referred to as the mobile termination service. If the CPP pricing system is in place (as in Australia) the calling party pays for the full, end-to-end cost of the call including charges to the mobile network operator for the provision of the mobile termination service. In countries where the RPP pricing system is in place, the called or receiving party pays for the cost of the carriage over the mobile network and the calling party pays the applicable tariff for carriage of the call over the fixed network.

The first outstanding characteristic of mobile telecommunications in the three countries considered is that the price of completing calls ('termination') on mobile networks is substantially higher than its cost, and that this arises because each mobile carrier possesses market power with respect to the termination of calls on its network. This market power is independent of the number and size of mobile carriers in the retail market because each mobile carrier has exclusive control of access by callers to subscribers on its network. In effect, there is no national market in termination; just a number of individual markets for termination on each carrier's network. The consequent above-cost pricing has generated above-normal profits from termination. Throughout this paper cost is defined as total service long run incremental cost (TSLRIC) with 'TSLRIC+' denoting there is a contribution to organisational-level costs.

Second, these termination profits have been used, at least in part, to subsidise (in the sense of Faulhaber, 1975) the pricing of retail mobile services. Subsidisation has been directed at both subscription to the mobile network (for example, free handsets; free connection; and lower-than-cost monthly charges), and to calling from mobile handsets. Mobile carriers contend that the profits on termination are completely dissipated in the retail or origination market, leaving each carrier with only normal profits overall. However, against this there is evidence of overall positive economic profits, doubts about the effectiveness of competition and the differing ability of rival mobile carriers to subsidise retail through, for example, differences in the balance of outgoing and incoming termination minutes.

Third, mobile carriers and their consultants in all three countries contend that the subsidy to the mobile network is justified by the presence of a mobile network externality, because existing mobile subscribers place a value on a new subscriber in addition to the new subscriber's own (marginal) private valuation. This they claim justifies a network externality surcharge (NES) over-and-above the cost of termination. The foundations are weak where 'saturation' has occurred and where subsidies are increasingly directed at customer 'churn' rather than at the few remaining mobile debutantes. There are also issues about the impact of other externality relationships that suggest otherwise. In particular, the mobile-call- 
receipt externality (considered later) suggests a subsidy, not a tax, on mobile termination (see Albon and York, 2005 and 2006).

Notwithstanding its justifiability on economic efficiency grounds, the resulting pricing structure taxes fixed-line callers in order to Faulhaber-subsidise mobile retail subscription and calling. With one important caveat (considered later), its impact is likely to have been causing the mobile network to be larger, and the fixed-line network to be smaller, than would have otherwise been the case. To the extent it has occurred, FTM substitution is likely to have been accelerated by the cross-subsidy established following above-cost pricing of termination; especially in the immature phase of mobile telecommunications where subsidies actually went to first-time subscribers rather than into customer churn.

\section{Fixed-to-Mobile Substitution}

Telecommunications analysts commonly depict the relationship between fixedline and mobile networks as 'fixed-to-mobile substitution', suggesting a replacement of fixed-line services with mobile services. The assessment of its validity requires study of the economic meaning of 'substitution' and of its applicability to the relationship between fixed-line and mobile telecommunications networks.

Traditional economic analysis tends to see substitution in terms of relatively simple commodities like 'tea and coffee', 'butter and margarine' or 'peas and beans', where an increase in the price of one relative to the other results in some replacement or substitution of the relatively more expensive one with the relatively less expensive one (see Newman, 1987; and Black, 1997:142, 451). Therefore, the intuition relates to a user shifting consumption from one service to another in response to a change in the relative prices of the two services.

Numerous difficulties of interpretation are encountered when relating the economic idea of substitution to telecommunications services:

(1) Calling depends on subscription or access to a network. In order to make a call it is first necessary to have access to an appropriate device, such as a mobile handset, a fixed-line handset or a PC connected to the telecommunications network (for Voice over Internet Protocol or 'VoIP'). Demand for making calls is influenced by the demand for subscription and for devices connected to a network for making calls, and the responsiveness of demand to changes in call prices is dependent on the price and availability of this subscriber access.

(2) Calling is not independent to the caller, as for every caller there must be someone called, who can be reached on one or more devices. The extent of substitution between different means of calling is related to the called party's access to receiving equipment (in general and in specific circumstances) and incentive to take the call (such as 'who pays?', and Caller ID availability).

(3) Both callers and those called value calls. Demand for any particular call is the sum of the willingness to pay of both parties to the call. In any given 
relationship, the two parties can alternate between one-another - callers can call and ask to be called back; calls can be elicited by an SMS message. This further limits the applicability of the traditional concept of substitution to the understanding of typical calling relationships, but is useful for understanding the application of complementarity in telecommunications.

(4) The extensive range of pricing plans for calling (especially from mobiles) may produce uncertainty about the cost to the caller of making different types of calls at different times and from different places; thus further complicating the calling decision.

(5) Substitutability is more readily applicable where the services are very similar, and this may not accord with reality. For example, it is often suggested that there is a 'mobile premium', relating to the special features of mobile telecommunications that make calling between mobiles more valuable. Alternatively, concerns about voice quality and line 'drop-out' may have the opposite effect on the relative value of mobile calls.

When viewed in the light of these factors, the conventional economics of substitution is of limited assistance in understanding the phenomenon of 'fixed-tomobile substitution'. When data for the countries considered here are examined, the trends are not supportive of decisive 'fixed-to-mobile substitution'.

In the early years of mobile telecommunications (until about 2001) traditional fixed-line calling continued to grow strongly based on high household and business penetration, and on substantial falls in call prices. Internet access was largely through dial-up based on low local call prices. Some of the growth also appears to have been related to the complementarity (considered later) between fixed-line and mobile telecommunications, where the value of the emerging mobile network depended heavily on interconnection with the established fixedline network. FTM and mobile-to-fixed (MTF) calling expanded very rapidly in spite of very high prices. High termination charges and below-cost mobile subscription meant that fixed-line callers were funding Faulhaber-subsidies to mobile subscription, although (see below) the inhibition of FTM calling by this pricing would also have served to lessen the valuation placed on mobile subscription.

Eventually, beginning around 2001 (possibly slightly later in New Zealand), the rate of growth of traditional (public switched telecommunications network or 'PSTN') fixed-line traffic and subscription declined. Because mobiles relate more closely to individuals than to households, the population penetration of mobiles eventually exceeded the population penetration of fixed-line services, with many households possessing more than one mobile subscription. The tipping point in the countries under consideration was in 2000 or 2001, and mobile penetration levels are now at around 90 per cent of the population, compared with 50-55 per cent for fixed-line services. Traffic minutes on fixed-line networks overwhelmingly exceed those on mobile networks in all three countries under consideration. 
Within fixed-line telecommunications, while traditional narrowband traffic eventually began to fall, increasingly broader-band traffic and subscription has increased; firstly through ISDN and then through DSL, which has moved into a rapid growth phase since 2004. In Australia, broadband has also been facilitated through the hybrid fibre-optic (HFC) cable networks built by Telstra and Optus in the mid-1990s. For Australia's incumbent, Telstra, total narrowband and broadband fixed-line revenues continued to grow until 2004-05 and appear now to be roughly constant at a little over 50 per cent of total revenue, with the composition changing more rapidly from narrowband to (DSL) broadband. Voice calls over the internet (VoIP) appear to be a substitute for PSTN calls, but it is not possible to get accurate data on the extent of VoIP calling.

Within mobiles, voice calls and subscription revenues have now stopped growing, and the 'mobile premium' has steadily decreased, although less decisively in New Zealand compared with Australia and the UK (Citigroup Smith Barney, 2004). Mobile subscription - at around 90 per cent of the population is widely regarded as being at 'saturation' level. However, 'data' revenues (mainly SMS or 'texting') have grown very strongly, and now contribute about 20 per cent of mobile revenues in all three countries. Pricing is increasingly on an 'all-you-can-eat' or 'bucket plan' arrangement where calls are not charged individually unless a capped amount is exceeded within the billing period. Texting is, to some extent, a substitute for voice calling, but can also be complementary where a text message is used to elicit a voice call.

An indication of the limitation on fixed-to-mobile substitution in the three countries considered is the small proportion of households that only have mobile subscription - that is, no fixed-line subscription at all. All three have low proportions of mobile-only households (around six per cent) compared with a European Union average of 12 per cent in 2004, with some EU countries having proportions of more than 20 per cent (see Burley, 2005; Citigroup Smith Barney, 2005; and Dobardziev, 2004 and 2005). Evidence from the United States (see Rodini, Ward and Woroch, 2004) suggests that second fixed lines into households have been abandoned for mobiles; not first lines.

In summary, there are indications both of replacement (for example, declining fixed-to-fixed minutes beside increasing mobile-to-mobile minutes, and the presence of some mobile-only households) and of complementarity (growing FTM and MTF calling). Further, intra-network substitution is clear within both fixed-line and mobile networks. One clear feature is that FTM and MTF calling have grown strongly throughout, reflecting the complementarity between fixedline and mobile networks.

\section{Complementarity between Mobile and Fixed-line Networks}

Complements are things that are consumed together, like 'left and right shoes', 'table knives and table forks', and 'petrol and cars', so that an increase in the price of one will result in a decrease in the amount of it consumed and a decrease in the consumption of its complement; and vice versa. For perfect complements the 
indifference curves are L-shaped; 'hinged' on a ray from the origin (slope of one for left and right shoes) with vertical and horizontal segments from each point on the ray.

\section{Complementarity in Telecommunications}

The economic concept of complementarity is readily applicable in telecommunications because the essence of telecommunications is in two-way or reciprocal relationships - making calls is complementary with receiving devices, and receiving calls is complementary with transmitting devices. Increasing the price of making calls will tend to reduce the demand for calls and, in turn, reduce the demand for subscription to services for receiving calls. Ergo, increasing the price of subscription will reduce its demand and, in turn, reduce the demand for calls because there are fewer subscribers to call.

The tax-termination-to-subsidise-subscription model requires the following symmetry to hold: Because subscription and FTM calling are complements (consumed together), if higher subscription (resulting from subsidisation) will induce greater FTM calling, then greater FTM calling (resulting from a decrease in the FTM price) must induce greater demand for subscription. It is just the same phenomenon (complementarity between FTM calling and mobile subscription) viewed from different perspectives. The interdependence is encapsulated by Hausman (2004:para 47):

Almost no mobile subscriber would purchase mobile service for only originating service or only for terminating service. When a potential consumer subscribes (s)he would make the decision whether the monthly subscription price is less than the combined value received ... from originating calls and terminating calls, which she receives for 'free'.

This implies that a 'dollar's worth of incoming calls' (measured in terms of user surplus) should have the same impact on the subscription decision as a dollar change in the price of subscription. The symmetry of complementarity is inherent in the traditionally-accepted approach (for example, Taylor, 1994) to deriving the demand for subscription. For given call prices, a potential subscriber's willingness to pay is equal to the sum of the surplus from outgoing and incoming calls giving rise to a matching demand for each individual. The aggregate demand curve for subscription is found by arraying each individual demand from highest to lowest, the locus of the top points tracing out the subscription demand curve. Changes in prices (including of substitutes and complements) will shift the demand curve up and down - for example, a reduction in outgoing call prices will, ceteris paribus, shift the subscription demand curve up.

\section{Asymmetric Complementarity}

The first direction of complementarity - that increased subscription elicits greater FTM calling encouraged by the greater availability of destination mobiles for calls 
by fixed-line subscribers - is inherent in all of the modelling of the mobile industry, including the 'Rohlfs model' developed by the United Kingdom's Office of Telecommunications (Oftel, now Ofcom) and in modelling commissioned by a number of carriers. However, the second direction of complementarity - that greater FTM calling increases the willingness to pay (demand) for subscription is not universally accepted. For example, Oftel (2001:69, fn 28) considers it

... is also theoretically possible that the demand for mobile subscription is affected by the receipt of incoming calls and so the pricing of such calls to the callers. But the empirical evidence (such as consumer research) that this effect is material is not strong and so it is not modelled.

More explicitly, CRA International (2006a:3) argues that

[m]obile termination is therefore an economic complement to subscription. Lowering subscription price increases the demand for termination. However the relationship is asymmetric and the reverse is not true: there is good evidence that lowering termination charges does not significantly increase demand for subscription.

This position is untenable both in principle and empirically.

Considering first the theoretical argument, the asymmetric complementarity hypothesis effectively requires a difference in the value of making a call relative to the value of receiving it. Given the reciprocity of typical calling arrangements considered earlier, this seems implausible. From the mobile subscriber's perspective, indifference between a dollar's worth of calling surplus and a dollar change in the subscription price is expected; reflecting the traditional approach to the demand for subscription considered earlier.

With respect to the empirics, CRA International does not present any of the 'good evidence' it refers to, and that presented in the UK by both Oftel/Ofcom and the Competition Commission is very thin and quite dated. The more relevant available evidence does not support CRA International's position. Indeed, it suggests that reductions in termination charges in all three countries over the past seven years have been associated with decreases in retail prices and increases in mobile subscription. This is the converse of what would be implied by the asymmetric complementarity hypothesis. In Australia's case, termination charges have more than halved since 1999, retail prices have also decreased substantially and mobile penetration of the population has more than doubled from around 40 per cent to over 90 per cent.

\section{The Waterbed Effect}

The UK Competition Commission (2003:2.563) seems to have been the first to use the evocative 'waterbed effect' terminology, where the regulated reduction in mobile termination charges has the effect of forcing the mobile carrier to increase 
subscription and other retail prices to make up the lost revenue. Implicitly or explicitly this has often been presented as a 100 per cent offset effect, where the impact is influenced by the extent of competition in the retail market. However, since it has been questioned by some regulators and access seekers, there have been attempts to argue it more formally including by Hausman (2004) and by CRA International (2006a and 2006b).

As a preliminary point, the waterbed is a distraction from the real issues. To the extent that high termination charges and low subscription prices cannot be justified on either network externality surcharge or Ramsey-Boiteux ('inverse elasticity') grounds, they are both sources of inefficiency. Therefore the downward pressure on termination charges from regulatory action and any associated upward pressure on mobile subscription and retail call prices are both sources of efficiency gain, and the effect is something to be welcomed rather than feared.

Turning to the positive economic analysis of this phenomenon, it is necessary to go back a step. Were the price of termination not regulated, standard microeconomic theory suggests that a profit-maximising mobile carrier will reduce retail mobile service prices below cost only if the reduction increases profits overall. Reducing retail mobile prices has a negative primary impact on profits; most graphically in the form of the cost to the mobile carrier of handset subsidies or reduced revenue from below-cost subscription fees. However, the increase in mobile subscription resulting from the price reduction induces an increase in the demand for termination, resulting in increased profits given the price of termination is greater than its cost. The profit-maximising mobile carrier would trade-off this increase in termination profits with the loss in profits from selling subscription below cost.

The positive economic analysis of the waterbed effect begins from the point where a mobile carrier has reduced its subscription price in the quest for greater profits. Were the termination charge to be reduced by regulatory action, while still remaining above cost, the overall change in profits from changing the subscription price would be equal to the (negative) change in profits from subscription, plus the (positive) change in profit from termination (as long as termination services are priced above their underlying cost, this will lead to greater termination profits). Given this, it would be irrational necessarily to respond in the retail mobile services market with actions designed to restore aggregate revenue to its level prior to the reduction in the termination charge. Any attempt to retrieve revenue by increasing mobile subscription prices will be thwarted - at least in part - by losses in FTM revenue as the demand for FTM calls decreases due to a decline in the number of destination mobile subscribers. If termination demand became sufficiently more responsive to price as it fell, this could be greater than the marginal profit gain from increasing the subscription charge (such as by reducing any handset subsidy), and no retail price increase would occur.

The position of CRA International (and others) in assuming asymmetries in complementarity could present a contradiction where a mobile carrier can increase its profits both by lowering subscription charges (because increased termination 
profit outweighs the direct loss from the subscription subsidy) and by increasing subscription charges (because it assumes away the offsetting losses of termination profits given that price of termination remains above cost). Somewhat implausibly, decreasing and increasing the subscription charge increases profits.

The symmetry of the interaction between termination and subscription is recognised by Hausman (2004:para 5) when he argues that the

... more subscribers a mobile company has, holding other factors equal, the more mobile terminating minutes it supplies. When a mobile company decides whether to increase its subscription [and originating] price to increase its revenue, it must take into account the reduced number of subscribers and the reduction in terminating minutes that will occur.

This means that a decrease in termination charges will lead to an increased willingness to pay for subscription. However, Hausman's analysis does not reflect all of the circumstances facing a mobile carrier under the calling party pays (CPP) arrangement, and misses a key offsetting effect. The model presents demand for subscription as a function of the price of subscription, the price of outgoing calls, and the 'per call terminating charge'. However, under CPP the receiving party does not pay for incoming calls, so that term relating subscription demand to a price that is not actually faced should not be part of the analysis. Instead, the demand for subscription should be related to the number of incoming calls, which is controlled by fixed-line callers. Given that these incoming calls are 'free' to mobile subscribers, they should generate more benefit to those receiving them (that is, mobile subscribers) than to those making them (fixed-line subscribers). This effect would tend to increase the willingness to pay for subscription from the fall in the FTM price by more than the amount allowed by Hausman's analysis. This additional impact is not captured by his algebraic analysis, thus leading to a possible overstatement of any waterbed effect.

In addition, Hausman's analysis overlooks the impact of the change in the per-unit input cost of supplying off-net MTM calls that flows from the reduction in the termination charge across other carriers. This would lead, other things being equal, to a reduction in the off-net MTM retail price of up to the amount of the reduction in the mobile termination charge, and this would further increase the willingness to pay for mobile subscription; thus further offsetting any waterbed effect.

In summary, existing analyses of the waterbed effect do not capture the full effects of a reduction in the termination charge, particularly because they have not taken a complete and consistent view of the complementarity between FTM calling and subscription. In the event of existing pricing below cost, any increase in subscription and retail call charges is a source of greater efficiency, not something to be concerned about. 
Implications for Empirical Modelling - Comment on Rohlfs's Model

An empirical model developed by Oftel to guide regulatory decisions is based on earlier work by Jeffrey Rohlfs and later developments by him for Oftel. From the beginning, this model adopted an asymmetric approach to complementarity. Rohlfs, who has been the foremost analyst of telecommunications externalities for thirty years, claims that (2002b:7):

The base-value of ... [the cross-elasticity of subscription with respect to the FTM price] is zero, because FTM usage is external to the subscription decision of marginal mobile subscribers ...

Thus a whole generation of empirical modelling based on Rohlfs's work has built-in this characteristic in the form of a zero cross-price elasticity between mobile subscription demand and the price of FTM calling. In turn, this is based on some dubious economic thinking and on some unsophisticated empirical research that actually indicates that there is an effect, but that it is not strong. As explained earlier, the symmetry of complementarity is more than 'theoretically possible', it is a logical necessity. Further, the empirical evidence is compelling. As concluded by Mitchell and Srinagesh (2003:17, original emphasis),

... models that assume that mobile subscribers obtain no benefit from calls made to them by fixed-network subscribers are, therefore, of limited value, and the use of traditional demand functions and the measure of consumer welfare derived from such models can be quite misleading ...

\section{Evaluation of the Case for a Network Externality Surcharge}

The argument for a surcharge on termination to fund a subsidy to mobile subscription relies on several underlying conditions being satisfied. These include: the establishment of the existence of a relevant network externality; the requirement that other external effects do not counteract - in a 'second-best' sense - the case for subsidising the externality; and that the subsidy does actually increase mobile subscription.

When viewed in the light of symmetric complementarity the last condition cannot be assumed, even where termination profits flow into subsidies to new subscription. Increasing the termination charge for FTM calls is a 'two-edged sword' where the stifling of FTM calling is likely to lead to a reduction in the value of mobile subscription at the same time as the subsidy funded by the termination profits encourages mobile subscription. Especially under CPP that bestows 'free' FTM calls on mobile subscribers, the offsetting effect is likely to be substantial. 


\section{Convergence}

While the generic meaning of 'convergence' is any 'coming together', its application in telecommunications is not straightforward. While it is clearly true that aspects of fixed-line and mobile networks are converging, it is difficult to see that 'wireline' and 'wireless' could ever be the same or come together — either there is wire or there is not. However, what has occurred is an increase in the relative importance of calls between fixed and mobile networks (FTM and MTF) and interesting developments such as 'mobile broadband' in its various guises; albeit with a distinct trade-off between bandwidth and mobility still evident at this stage. Other impending developments include the introduction of SMS calls from fixed-line phones and of VoIP calls going into and out of the mobile network. Combinations of wired and wireless technologies will continue to be used to produce new and improved services, and this will be largely seamless to users. Nonetheless, while convergence has some general meaning, it is contended in this paper that, properly interpreted, the more promising ideas for analysing the interaction between fixed-line and mobile networks lie with complementarity and substitutability, rather than with convergence.

\section{Conclusion}

This paper gives rise to the following conclusions on the economic relationship between fixed-line and mobile networks for countries with high fixed-line household penetration prior to mobile telecommunications, CPP pricing, and high levels of mobile penetration:

- The complex array of network-based telecommunications services are not readily interpreted by traditional economic notions of 'substitutability' and 'complementarity'. However, when they are properly interpreted substitution and complementarity (particularly the latter) become powerful analytical tools for understanding the relationship between fixed-line and mobile telecommunications networks that is so vital in a variety of important policy contexts.

- Convergence seems to have become a convenient contemporary catch-cry and cure for any problem. However, convergence appears to be insufficiently well-defined to be a clearly useful device for organisation of thoughts about relationships within and between traditional fixed-line; broadband and mobile networks. Considerations of convergence usually come back to notions of substitutability and complementarity.

- The relationship between fixed-line and mobile networks does involve some true 'substitution'. To the extent that revenue from traditional fixed-line revenue and traffic has declined, it has tended to migrate increasingly into broader-band fixed-line services as well as into mobiles. Broadband has not only been associated with the internet and e-mail, but also with VoIP; arguably a 'substitute' for traditional PSTN calls, particularly for long- 
distance and international calls. Incumbents tend to concentrate on the downside in support of a deregulatory stance.

- Within mobiles there has been a trend towards plateauing of voice traffic and revenues, and trends towards 'bucket plan' pricing and greater use of data services, especially SMS ('texting') which now account for around 20 per cent of mobile revenues in the three countries considered.

- The more dominant characteristic between fixed-line and mobile networks appears to be one of complementarity, relating to calls between fixed-line and mobile networks - fixed-to-mobile (FTM) and mobile-to-fixed (MTF). In the immature phase of mobile telecommunications the value of mobile subscription is heavily dependent on the ability to receive calls from, and make calls to, the dominant fixed-line network. There are simply not enough mobiles to call and receive calls from. This relative dependence on the fixedline network gradually lessens as mobile penetration increases, but calls from and to mobiles remain a major driver of willingness to pay for mobile subscription.

- The regulatory debate has been preoccupied with network externalities and call externalities (especially the mobile network externality) and crosssubsidy (above-cost FTM termination charges raising net revenue used to fund subsidies to mobile subscription and mobile-to-mobile (MTM) pricing). The extent of fixed-line subsidisation of mobile networks has decreased as mobile termination charges have fallen, and mobile carriers have concentrated subsidies on customer churn rather than the dwindling number of potential debutante mobile subscribers.

- Complementarity remains a crucial element because of the dependence of mobile subscription demand on the value of incoming calls and of the dependence on FTM call demand on the number of destination mobiles. This symmetry of complementarity is essential to understanding the so-called 'waterbed effect', to the proper specification of any empirical model of efficient pricing (such as the Rohlfs model), and in interpreting the success of cross-subsidy in promoting mobile subscription.

- This paper has not considered countries that had undeveloped fixed-line networks prior to mobile telecommunications, and where there was apparently a 'leap-frogging' of mobiles over the fixed-line network - that is, wireline networks have often not been developed much further than where they were pre-mobiles, and the growth has mainly focused on wireless. It is also inapplicable to countries like the United States and Canada, which, while having highly-developed fixed-line penetration, adopted a receiving party pays (RPP) procedure for mobile termination, therefore avoiding a Faulhaber cross-subsidy of the mobile network by the fixed network. 


\section{References}

Albon, R. and R. York (2005), 'Should Mobile Subscription be Subsidised in Mature Markets?’, ITS Asia-Indian Ocean Regional Conference, Perth, 28-30 August (forthcoming in Telecommunications Policy).

Albon, R. and R. York (2006), 'Mobile Termination: Market Power, Externalities and their Policy Implications’, Telecommunications Policy 30:368-384.

Black, J. (1997), Oxford Dictionary of Economics, Oxford University Press.

Burley, N. (2005), 'Fixed-to-mobile Substitution in Australia', Ovum, 13 October.

Citigroup Smith Barney (2004), Fixed to Mobile Substitution, Sydney, 11 October.

Competition Commission (UK) (2003), Vodafone, O2, Orange and T-Mobile: Reports on References under Section 13 of the Telecommunications Act 1984 on the Changes Made by Vodafone, O2, Orange and T-Mobile for Terminating Calls from Fixed and Mobile Networks.

CRA International (2006a), 'The 'Waterbed Effect' in Mobile Telephony', Competition Policy Discussion Paper, Wellington New Zealand, January.

CRA International (2006b), 'Der 'Wasserbetteffekt' im Mobilfunkmarkt', Diskussionspapier, London, February.

Dobardziev, A. (2004), 'Defending Against Fixed-mobile Substitution', Ovum, 20 February.

Dobardziev, A. (2005), 'Fixed-to-mobile Substitution Benchmark: Europe’, Ovum, 11 January.

Gans, J., S. King and J. Wright (forthcoming), 'Wireless Communications' in M. Cave, S. Majumdar and I. Vogelsang (eds) Handbook of Telecommunications Economics, Volume 2, Elsevier, Amsterdam.

Hausman, J. (2004), Economic Analysis of Regulation of CPP, Submission to New Zealand Commerce Commission on behalf of New Zealand Telecom, November 29.

Mitchell, B. and P. Srinagesh (2003), Economic Analysis of Fixed-to-Mobile Call Termination, prepared for BellSouth International by Charles River Associates, CRA No. 4021, Palo Alto California, 28 March.

Newman, P. (1987), 'Substitutes and Complements', pp. 545-548 in J. Eatwell, M. Millgate and P. Newman (eds), The New Palgrave Dictionary of Economics, Volume 4, Macmillan.

Oftel (2001), Review of the Charge Control on Calls to Mobiles, 26 September.

Ofcom (2004), Wholesale Mobile Voice Call Termination, Statement, 1 June.

Ofcom (2005), Wholesale Mobile Voice Call Termination Markets - A Proposal to Modify the Charge Control Conditions, Explanatory Statement and Notification of Proposals, Consultation Document, 7 June. 
Phoenix Center (2004), 'Fixed-Mobile “Intermodal” Competition in Telecommunications: Fact or Fiction?’, Phoenix Center Policy Bulletin No. 10, 31 March.

Rodini, M., M. Ward and G. Woroch (2004), 'Going Mobile: Substitutability Between Fixed and Mobile Access’, Telecommunications Policy 27:457-476.

Rohlfs, J. (1979) 'Economically-efficient Bell-System Pricing', Bell Laboratories Economic Discussion Paper No. 138, January.

Rohlfs, J. (2002a), 'Network Externalities and their Internalization with Respect to the U.K. Mobile Market', Strategic Policy Research, April 19.

Rohlfs, J. (2002b), 'A Model of Prices and Costs of Mobile Network Operators', Strategic Policy Research, May 22.

Rohlfs, J. (2002c), 'Response to Two Questions Posed by the Competition Commission Benefits to Fixed Subscribers and Econometric Estimates', Strategic Policy Research, September 5.

Taylor, L. (1994), Telecommunications Demand in Theory and Practice, Kluwer Academic Publishers, Boston.

This is a revised version of a paper presented at the ITS Biennial Conference in Beijing, June 2006. I am grateful to Richard York for discussions and collaboration on these issues over several years. The views expressed in this paper are my own, and do not necessarily coincide with those of the Australian Competition and Consumer Commission. I am also grateful to two anonymous referees for their valuable comments 